\title{
Under Maintenance: Come in Now!
}

SERGIO LOPEZ-PINEIRO

Harvard University

The relationships that exist between the academic and the industrial worlds are often set in practical and mutually beneficial terms: companies fund advanced academic research in exchange for permission to commercially exploit any useful findings. Despite the unquestionable educational and commercial values provided by this type of relationship, I would like to propose in this article a different vantage point from where to establish a relationship between design (as a form of cultural inquiry) and industry (as a form of applied research).

The role of this vantage point would be to reveal unexpected spatial and temporal gaps in the functioning of specific spaces. But, while a traditional industrial model would attempt to fill in these gaps, 'fixing' them in order to maximize the efficiency of the spaces, I propose protecting them with the intent of occupying them with unexpected and unrelated programs.

Parking infrastructures along with their maintenance services is the industry I will be briefly examining as an example with which to make the argument. The myth of architecture as a "black box"-along with its complete and stable appearance-has helped establish the status of the many different artifacts of the built environment (buildings, parks, and so on) as intense urban singularities. Completeness and stability are generally expected to define the character of architectural artifacts. In this context, a new type of relationship with the industrial realm can be the means to define a new architectural character that would open up architecture's "black box."

The relationships that exist between the academic and the industrial worlds are often set in practical and mutually beneficial terms: companies fund advanced academic research in exchange for permission to commercially exploit any useful findings.

For example, following the ongoing advancements of various techniques of digital fabrication, the new relationships being established between schools of design and fabrication industries are the latest episode in this symbiotic relationship between the academic and the industrial worlds. In this particular case, students with cutting edge skills help overhaul companies stuck in traditional production methods; fabrication companies with advanced machinery provide access to schools relieving them from covering large financial costs, etc.
Despite the unquestionable educational and commercial values provided by this type of relationships, two opposing points of view regarding the nature of academic education inevitably emerge: some argue that in this context academic inquiry risks becoming nothing else than applied research while others state that the need for new and improved commercial products always fuels the production of new knowledge.

With this dichotomy in mind, I would like to propose in this article a different vantage point from where to establish a relationship between design (as a form of cultural inquiry) and industry (as a form of applied research). The role of this vantage point would be to reveal unexpected spatial and temporal gaps in the functioning of specific spaces. But, while a traditional industrial model would attempt to fill in these gaps, 'fixing' them in order to maximize the efficiency of the spaces, I propose protecting them with the intent of occupying them with unexpected and unrelated programs.

Parking infrastructures along with their maintenance services is the industry I will be briefly examining as an example with which to make the argument. As it is well known, this industry is concerned with independent nodes (parking lots and structures) that, under certain circumstances, also form a network (as it relates to city transportation networks, urban districts, etc.). This industry extends across all the design disciplines dealing with the built environment (architecture, landscape architecture, urban design and planning) and consequently, it involves a very large range of scales, both temporal and spatial.

\section{MAINTENANCE PATTERNS}

After the revolution, who's going to pick up the garbage on Monday morning? ${ }^{1}$

-Mierle Laderman Ukeles, "Manifesto for Maintenance Art, 1969!"

Street maintenance services (such as cleaning, tree pruning, snow plowing, etc.) operate on a temporal scale: they must be scheduled and, as carefully planned events, they only take place within specific allotted slots of time. Paradoxically, altering the management of these services does not reveal temporal gaps but rather, it presents opportunities for new spatial intensities. 


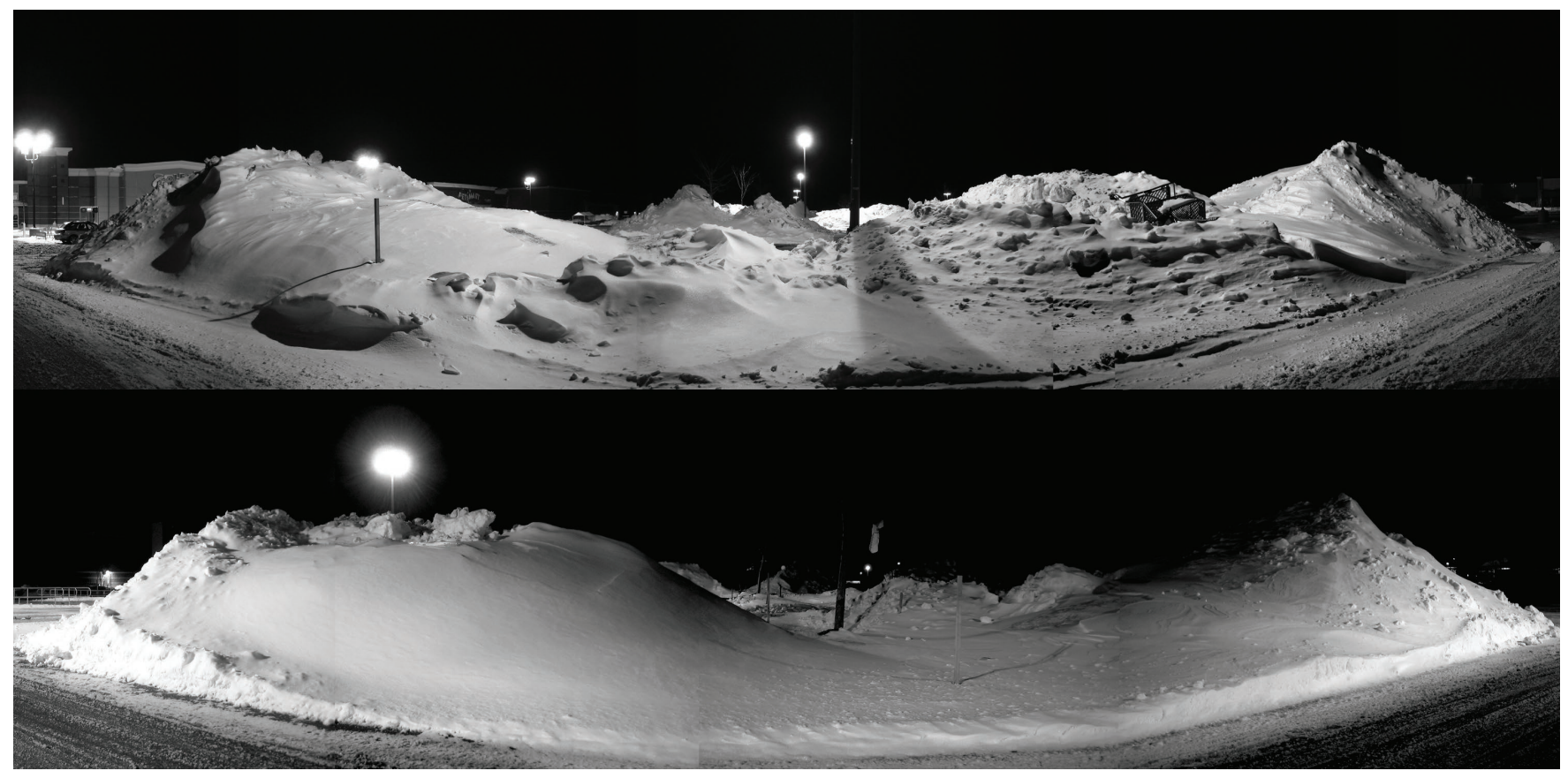

Figure 1. Sergio Lopez-Pineiro, "White Space” (2009).

In 1969, Mierle Laderman Ukeles wrote "Manifesto for Maintenance Art, 1969!" in which, amongst other things, she proposed a museum installation, free of traditional art, where she would perform all the usual everyday maintenance tasks. "I will sweep and wax the floors, dust everything, wash the walls (i.e. "floor paintings, dust works, soap-sculpture, wall-paintings") [...] The exhibition area might look "empty" of art, but it will be maintained in full public view."2 Maintenance became art.

"I do a hell of a lot of washing, cleaning, cooking, renewing, supporting, preserving, etc. Also, (up to now) separately I "do" Art. Now, I will simply do these maintenance everyday things, and flush them up to consciousness, exhibit them, as Art." ${ }^{3}$ While Ukeles' text and performances have been extremely influential within the field of gender studies and they hold a great significance within the continuous struggles for gender equality, her artistic proposition can also be projected to a larger public scale. Her position as artist in residence at the New York City Department of Sanitation since 1977 clearly demonstrates the promise of maintenance public services as potential urban creative agents.

In 2009 I published "White Space," a photo-essay that revealed how "everyday plowing practices-practices with no artistic or design ambitions-have the capacity to transform snowed-in parking lots into beautiful winter gardens."4

These images of unintentional snow landscapes resonate with Ukeles' statement regarding the potential artistic nature of maintenance practices. However, while Ukeles was conscious and committed to the artistic ambitions of her work these snow landscapes are accidental and it is only through an outsider's reading -in this particular case, my own-that they reveal their artistic potential. Based on this realization, I designed and implemented Olmsted's Blank Snow, a temporary landscape that uses the physical and material traces of snow plowing practices as the trigger for the transformation of maintenance services into design agents.

Olmsted's Blank Snow is a temporary winter landscape that took place during the winter of 2010-11 in the parking lot of Front Park, one of the six Olmsted Parks in Buffalo, New York. I initiated this project by proposing to the Buffalo Olmsted Parks Conservancy a snowplowing plan to locate the snow mounds resulting from daily plowing. The design exploits the spatial conditions defined by these typically overlooked snow mounds, temporarily transforming a barely used parking lot into a winter garden. Funded by NYSCA (New York State Council on the Arts), this project seeks to transform standard snow plowing techniques into creative tools for generating new winter public spaces.

In small parking lots, maintenance crews generally plow the snow toward the lots' outer edges as this snow's placement minimizes the amount of parking spaces to be overtaken by snow mounds. In large parking lots, however, maintenance crews need to plow the snow toward the center of the lots since, due to the lots' large size, pushing the snow all the way to the edge is not a feasible option. It is precisely this practical decision that enables the formation of accidental and temporary winter gardens. With the intention of revealing new spatial intensities, the snow plowing plan that we proposed to the Buffalo Olmsted Parks Conservancy broke these ordinary 


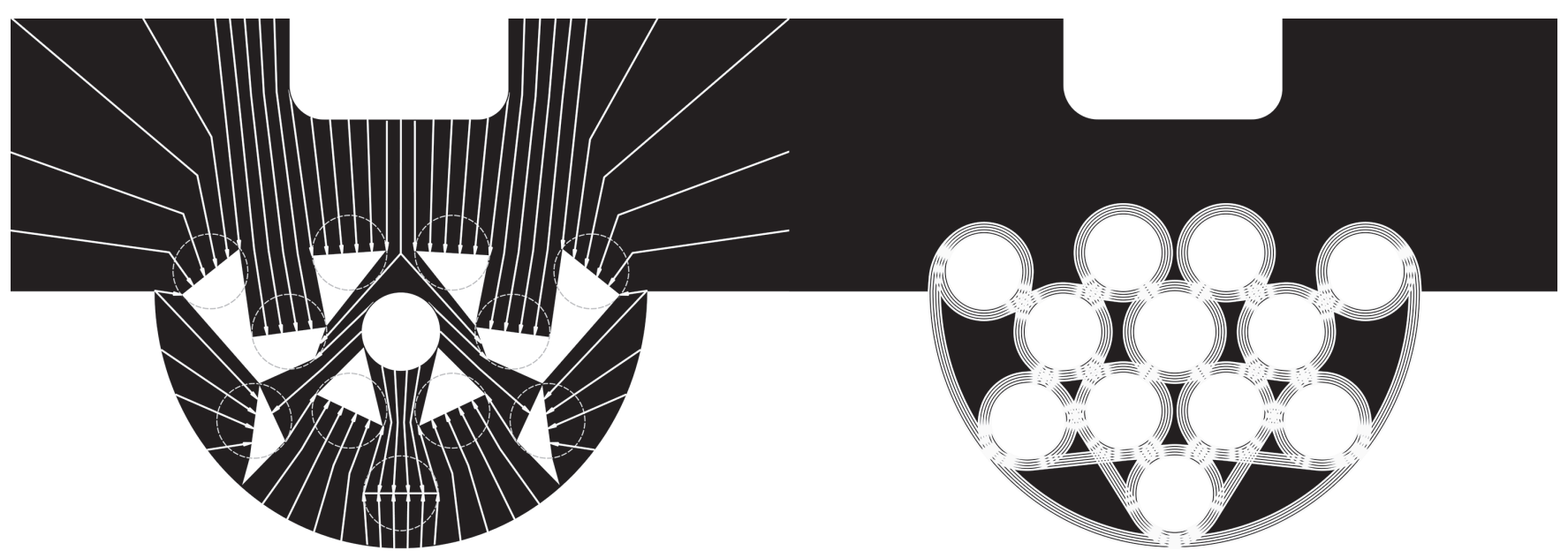

Figure 2. Frontal plowing (left) and encircling plowing (right). Sergio Lopez-Pineiro, Olmsted's Blank Snow, Buffalo (2010-11).

maintenance rules and located the mounds in positions different from the standard and practical ones, changing the amount of mounds as well as the spacing between them.

Two snow plowing techniques were used: frontal plowing and encircling plowing. Frontal plowing happened first in order to push as much snow out of the way as possible; encircling plowing followed next in order to properly shape paths and mounds. The footprints of the snow mounds depend on the turning radius of the plowing truck used. In this case, the two trucks most regularly used (2005 Chevrolet Silverado 2500HD and 2010 Ford F150) had very similar turning radii (21.9 and $20.85 \mathrm{ft}$.). The average plowing time was 3 hours-for a surface area of $100,000 \mathrm{sq}$. ft.

As previously argued, traditional models of interaction between the academic and the industrial worlds are in place to discover new practical potentials. In the alternative understanding that I am proposing in this paper, the objective of interacting with an industry would be to reveal its unexpected spatial and temporal gaps. But, while a traditional model would attempt to fill in these gaps, 'fixing' them in order to maximize the system's efficiency, I propose occupying them with unexpected and unrelated programs. In this particular case, Front Park's parking lot was transformed into a temporary winter garden through the manipulation of standard snow plowing techniques, revealing the potentials for a new type of winter public space. The resulting landscape was not the most efficient snow plowing practice but it achieved to artistically exploit the spatial conditions defined by these typically overlooked snow mounds.

In order to figure out how to face unknown variables (snow precipitation, drifts, amount of snow to effectively stay on the ground, etc.), we built a large model $(5 \times 6.5 \mathrm{ft}$.) that also served to communicate to the Buffalo Olmsted Parks Conservancy the temporary and fluctuating nature of the landscape they were about to implement. The landscape slowly emerged and it experienced different peaks of intensity throughout its short life, always suggesting that it was never finished.

As previously mentioned, maintenance services rely on careful scheduling. Altering these services, however, does not impact the space's temporal qualities but rather, it opens up the space in unexpected ways. As I hope to have shown, Olmsted's Blank Snow exemplifies how maintenance services can be transformed to reveal unfamiliar spatial intensities. It is worth noting that in the development of such transformations, the traditional boundaries between the disciplines dealing with the built environment (architecture, landscape architecture, urban design) necessarily become blurred. As such, this design strategy can be a powerful educational tool to explore new relationships between the academic and the industrial worlds.

\section{RHYTHMIC SCHEDULES}

Transportation infrastructures (such as railways, streets, parking structures, etc.) operate on a spatial scale: they are strategically placed and connected. Paradoxically, altering these infrastructures' functioning logics does not reveal a new space but rather, it offers new temporal gaps to be appropriated freely.

The Thai Maeklong Railway goes through the Maeklong Railway Market, one of Thailand's largest fresh seafood markets. This market has become globally famous due to the constant appropriation of the railway lines that the stall owners perform after each of the train's runs. In other words, the market operates in the temporal gaps that exist within the schedules of the Thai railroad companies. The overall railroad operational mode indicates that the singular event of the Maeklong Railway Market could be transformed into a network-at a national scale-of overlapping unrelated events. 


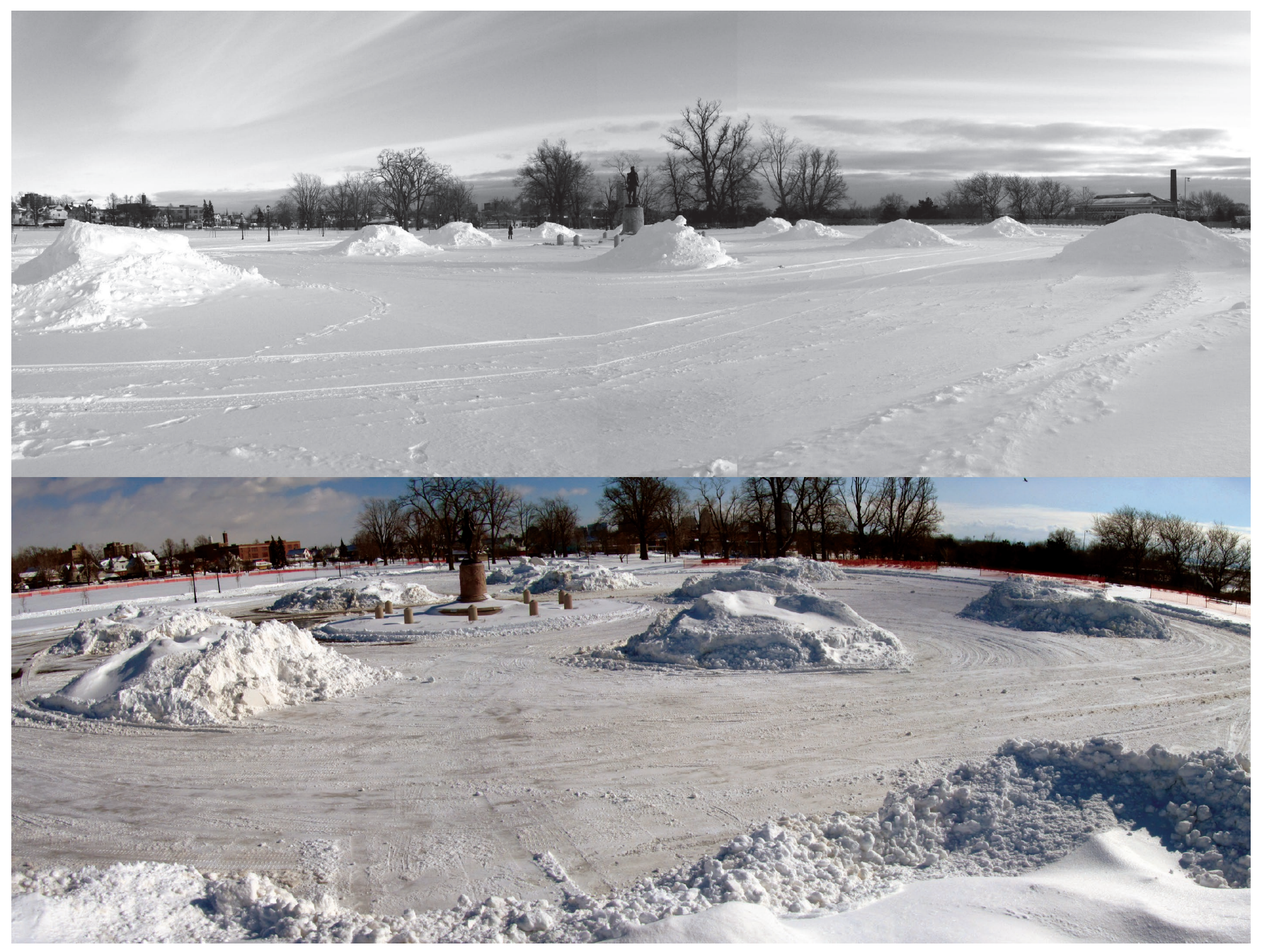

Figure 3. Two panoramic views taken on January 16, 2011 (top) and February 8, 2011 (bottom). Sergio Lopez-Pineiro, Olmsted's Blank Snow, Buffalo (2010-11).

The spacing in between predictable events-those for which the infrastructure was originally built-are to be understood as open slots of time that transform the infrastructure from an efficient system into a space available for unexpected and unregulated events. Similar to how the spacing in between the sweeping lights of a prison's surveillance towers allow for memorable escapes, the spacing in between a highly controlled schedule allows for the release of different urban pressures.

Blue Rainbow is a proposal for a new type of indoor/outdoor landscape. In cold cities, running and exercising outdoors during the winter can be an arduous task: ice, snow, and low temperatures make it difficult to roam throughout the city. This project proposes transforming abandoned generic parking structures into playscapes for year-round use by placing color bands of a synthetic track-like layer over the existing concrete surface. Although this transformation could take place at any deserted parking structure, the abandoned Osinski Ramp (760 cars) in Buffalo, New York, has been used as a case study for this proposal.
Due to the ramps' sizes, parking structures posses the spatial expansiveness of a landscape. With its tints of color, the Blue Rainbow emphasizes the repetitiveness of these parking structures while infusing them with a new spatial intensity, all without expensive alterations to the parking's original structure.

A seasonal inflatable structure placed atop the parking ramp prevents snow and ice from entering the playscape. As a new fresh layer of snow, the proposed layers of synthetic track-like material would blanket the space, offering new occupation possibilities.

In this particular case, the Blue Rainbow addresses a large temporal scale since the rethinking of the parking structure as an alternative public space occurs only after the structure's main function as a parking lot has been terminated. However, a parking lot could be rethought to fit temporal variations of various different rhythms (daily, monthly, annually, generationally...). For instance, 


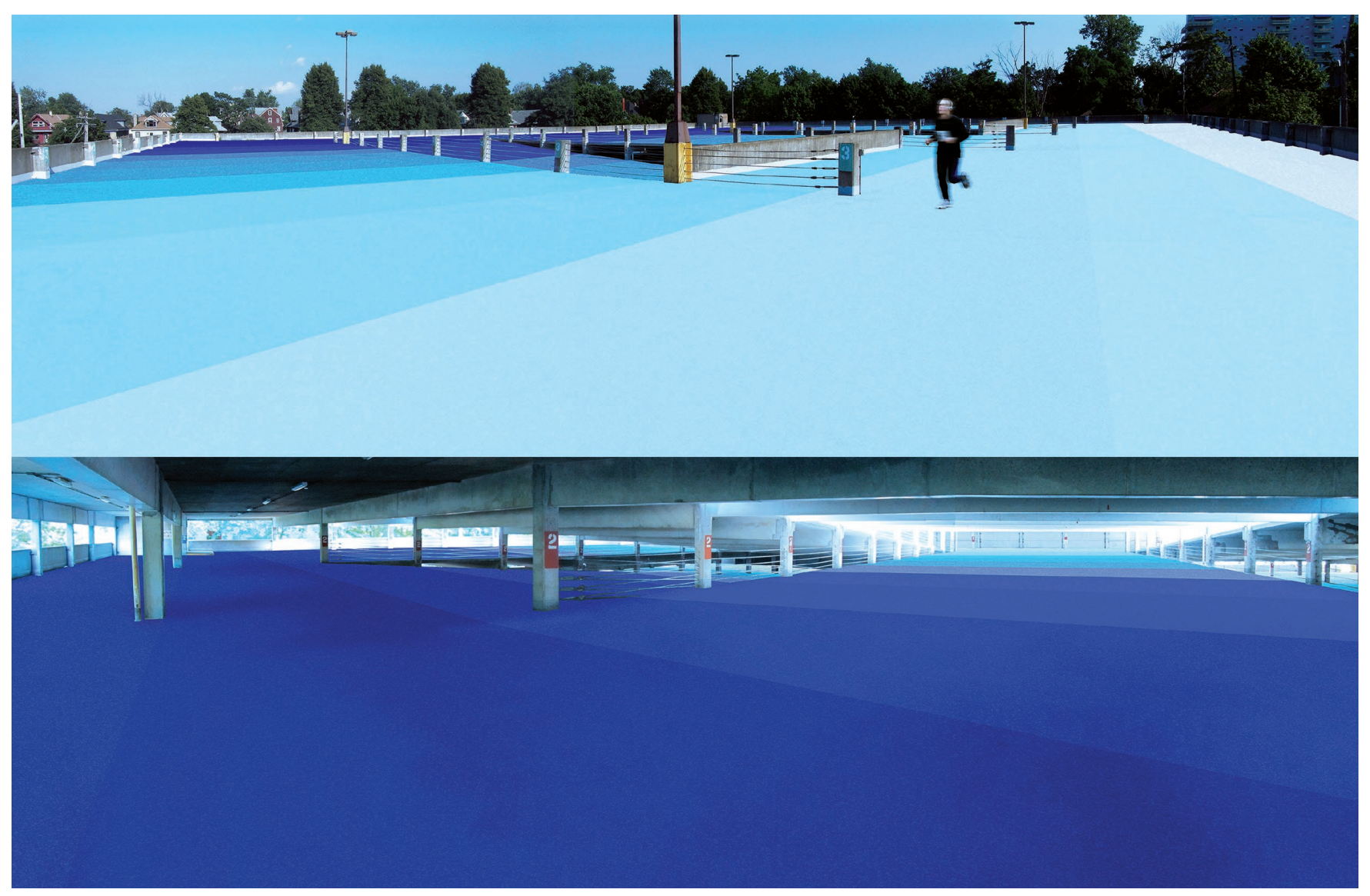

Figure 4. Sergio Lopez-Pineiro, Blue Rainbow, Buffalo (2013).

in Conakry, Guinea, many "young Guineans study under the dim parking lot lights at G'bessi Airport." ${ }^{5}$ Guinean students have discovered that the airport's parking lot is one of the few places where the lights never go out. Since access to power is uncommon and power outages are very frequent, the airport's parking lot doubles as an informal study room at night. This kind of overlapping of unrelated rhythmic events is only possible by altering the infrastructure's spatial logics.

\section{DIFFUSING SINGULARITIES}

Throughout its history, architecture is a discipline whose overall appearance-both in mythical as well as in concrete terms-has been built on completeness and stability. Many authors and movements have at different moments attempted to analyze and address this fundamental disciplinary quality. For example, Reyner Banham's point of view on this matter-which has influenced the theme and organization of this conference-portrayed architecture as a "black box," the outcome of a rather opaque intellectual and creative design process. ${ }^{6}$

Regardless of one's view on this description, the myth of architecture as a "black box"-along with its complete and stable appearance-has helped establish the status of the many different artifacts of the built environment (buildings, parks, and so on) as intense urban singularities. Completeness and stability are generally expected to define the character of architectural artifacts. In this context, a new type of relationship with the industrial realm can be the means to define a new diffused architectural character that would open up architecture's "black box." For this reason, and as I hope to have shown, altering temporal-based maintenance services can reveal unfamiliar spatial intensities and altering space-based infrastructures can enable unrelated rhythmic events.

In order to understand the mechanics of the procedures that result in these apparently contradictory outcomes, it is important to highlight the singular mindset of the industry's operational model. Parking infrastructures are designed for a singular program and their maintenance services are only concerned with what is required to satisfy that single program in the most efficient manner. The need to maximize a singular function in the most efficient way has a blinding effect generally precluding the appearance of any other previously unimagined possibilities. While I am referring in this paper to only one particular industry (parking infrastructures along with their maintenance services), the conclusions apply to most other industries. 
For this reason, the two complementary design methods described above (Maintenance Patterns and Rhythmic Schedules) reveal how to construct a new diffused architectural character, one that accepts maintenance rather than completeness in order to open up the "black box." In both cases, the design decisions must be understood as the constituents of a methodology for diffusing the singularities (both spatial and temporal) prevalent within architecture's appearance as well as within an industry's operational model. In the first case, interacting with maintenance services diffuses their singular purpose, enabling the emergence of unexpected spatial intensities. In the second case, the overlapping of unrelated events within the same infrastructure questions the infrastructure's singular schedule. In summary, the two propositions described in this paper for engaging architecture's traditional appearance through the manipulation of an industry's operational model can be simply described as methods for opening up architecture's "black box."

Consequently, and finally, it has to be concluded that an interesting framework for engaging industry through design appears when we approach it via these two propositions, demonstrating that there are other venues to be explored within the confluence of the industrial and the academic worlds that go beyond the standard practical ones.

\section{ENDNOTES}

1 Mierle Laderman Ukeles, "Manifesto for Maintenance Art, 1969!" accessed January 30, 2019. https://www.arnolfini.org.uk/blog/manifesto-for-maintenance-art-1969/Ukeles_MANIFESTO.pdf.

2 Ukeles, "Manifesto for Maintenance Art, 1969!"

3 Ukeles, "Manifesto for Maintenance Art, 1969!"

4 Sergio Lopez-Pineiro, "White Space," Places (November 2009). https://placesjournal.org/article/white-space/.

5 Eran Ben-Joseph, Rethinking a Lot: The Design and Culture of Parking (Cambridge, MA; London: The MIT Press, 2012), XIX.

6 Reyner Banham, "A Black Box: The Secret Profession of Architecture" in A Critic Writes: Essays by Reyner Banham (Berkeley: University of California Press, 1996), 292-299. 